\title{
Influenza A induces dysfunctional immunity and death in MeCP2- overexpressing mice
}

\author{
James C. Cronk, ${ }^{1,2,3,4}$ Jasmin Herz, ${ }^{1,2}$ Taeg S. Kim, ${ }^{5,6}$ Antoine Louveau, ${ }^{1,2}$ Emily K. Moser,, ${ }^{5,7}$ \\ Ashish K. Sharma, ${ }^{8}$ Igor Smirnov, ${ }^{1,2}$ Kenneth S. Tung, ${ }^{6,9}$ Thomas J. Braciale, , 4,5,6,9 \\ and Jonathan Kipnis 1,2,3,4 $^{1}$ \\ 'Center for Brain Immunology and Glia, ${ }^{2}$ Department of Neuroscience, ${ }^{3}$ Graduate Program in Neuroscience, \\ ${ }^{4}$ Medical Scientist Training Program, ${ }^{5}$ Beirne B. Carter Center for Immunology Research, ${ }^{6}$ Department of Pathology, \\ ${ }^{7}$ Department of Pharmacology, ${ }^{8}$ Department of Surgery, ${ }^{9}$ Department of Microbiology, Immunology and Cancer Biology, \\ University of Virginia, Charlottesville, Virginia, USA
}

\begin{abstract}
Loss of function or overexpression of methyl-CpG-binding protein 2 (MeCP2) results in the severe neurodevelopmental disorders Rett syndrome and MeCP2 duplication syndrome, respectively. MeCP2 plays a critical role in neuronal function and the function of cells throughout the body. It has been previously demonstrated that MeCP2 regulates $\mathrm{T}$ cell function and macrophage response to multiple stimuli, and that immune-mediated rescue imparts significant benefit in Mecp2-null mice. Unlike Rett syndrome, MeCP2 duplication syndrome results in chronic, severe respiratory infections, which represent a significant cause of patient morbidity and mortality. Here, we demonstrate that $\mathrm{MeCP2}{ }^{\mathrm{Tg} 3}$ mice, which overexpress $\mathrm{MeCP2}$ at levels 3 - to 5-fold higher than normal, are hypersensitive to influenza $\mathrm{A} / \mathrm{PR} / 8 / 34$ infection. Prior to death, $\mathrm{MeCP} 2^{\mathrm{Tg} 3}$ mice experienced a host of complications during infection, including neutrophilia, increased cytokine production, excessive corticosterone levels, defective adaptive immunity, and vascular pathology characterized by impaired perfusion and pulmonary hemorrhage. Importantly, we found that radioresistant cells are essential to infection-related death after bone marrow transplantation. In all, these results demonstrate that influenza $\mathrm{A}$ infection in $\mathrm{MeCP}^{\mathrm{Tg} 3}$ mice results in pathology affecting both immune and nonhematopoietic cells, suggesting that failure to effectively respond and clear viral respiratory infection has a complex, multicompartment etiology in the context of MeCP2 overexpression.
\end{abstract}

Conflict of interest: The authors have declared that no conflict of interest exists.

Submitted: April 26, 2016 Accepted: December 6, 2016 Published: January 26, 2017

Reference information: JCI Insight. 2017;2(2):e88257. doi:10.1172/jci.insight.88257.

\section{Introduction}

Methyl-CpG-binding protein $2(\mathrm{MeCP} 2)$ is an X-linked transcriptional regulator affecting a myriad of genes (1), and is capable of both genetic repression and activation (2). Transcriptional regulation by MeCP2 is critical for normal development and function, exemplified by the fact that both loss of function and overexpression of $\mathrm{MeCP} 2$ result in severe neurodevelopmental disorders known as Rett syndrome (3) and MeCP2 duplication/triplication syndrome (4), respectively (here we will refer to both MeCP2 duplication and triplication syndromes collectively as $\mathrm{MeCP} 2$ duplication syndrome). MeCP2 duplication syndrome is typically caused by a duplication of the Xq28 region of the $\mathrm{X}$ chromosome (5). MeCP2 duplication patients are overwhelmingly male owing to the X-linked nature of the disease; females inheriting MeCP2 duplication have been shown to skew X-inactivation heavily towards the chromosome containing the duplication, thus preventing nearly all symptoms of the disorder (5). Although significant research and clinical attention has been given to Rett syndrome, $\mathrm{MeCP} 2$ duplication syndrome remains understudied.

$\mathrm{MeCP} 2$ duplication syndrome is in part characterized by chronic respiratory infections, which cause significant morbidity and mortality in these patients $(5,6)$. It was previously shown that MeCP2 plays an important role in immune cells, including T cells (7-10) and myeloid cells (11-16), and thus it was hypothesized that chronic infections seen in MeCP2 duplication syndrome may be explained by the direct role of MeCP2 in immune cells. In 2012, Yang et al. demonstrated that CD4 $4^{+} \mathrm{T}$ cells overexpressing MeCP2 in both mice and humans were deficient in IFN- $\gamma$ production after skewing to Th1 in vitro, and that $\mathrm{MeCP}^{\mathrm{Tg} 3}$ mice (17), which have a human $\mathrm{MeCP} 2$ gene inserted into their genome and overexpress $\mathrm{MeCP} 2$ at levels 3 - 

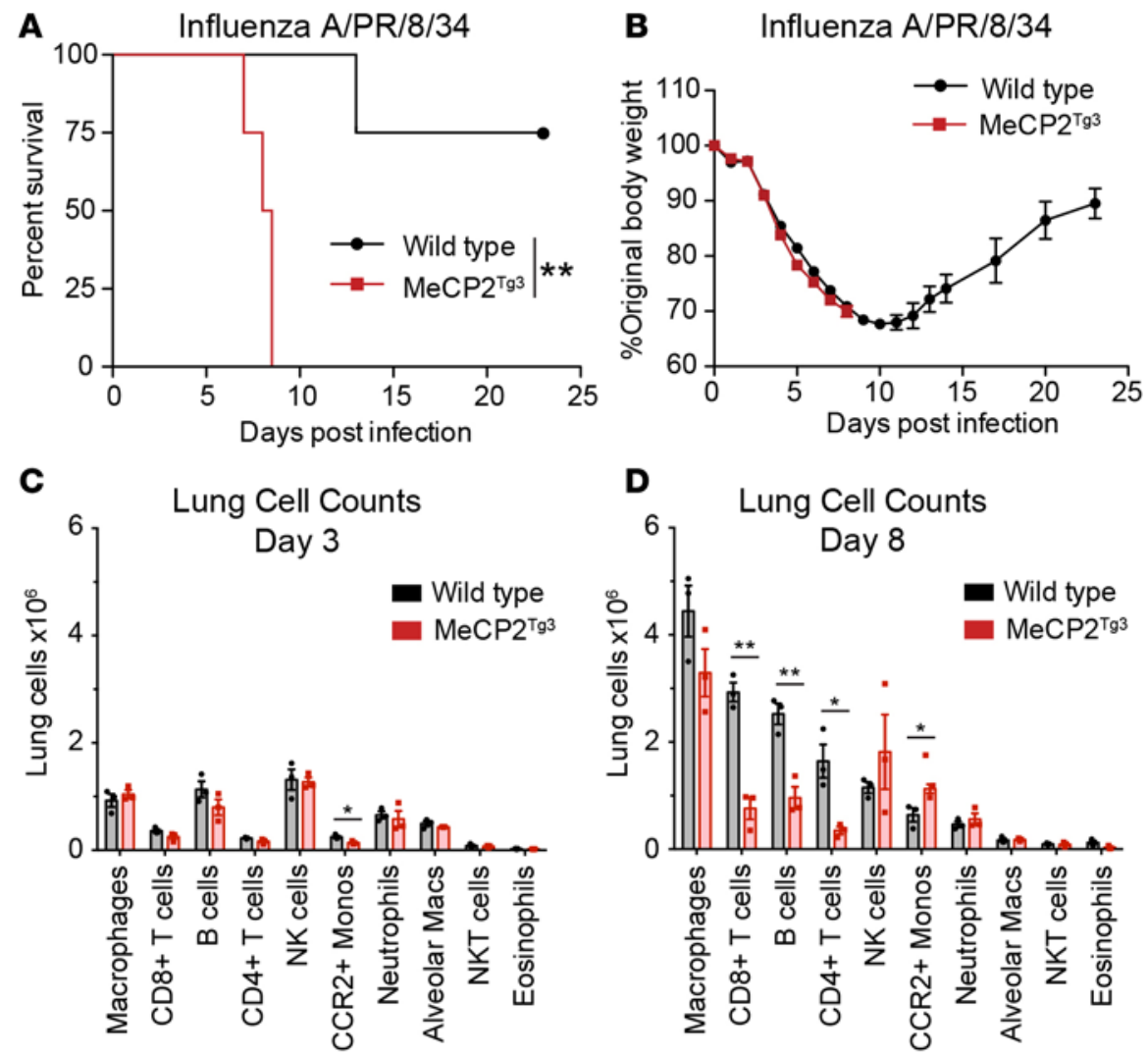

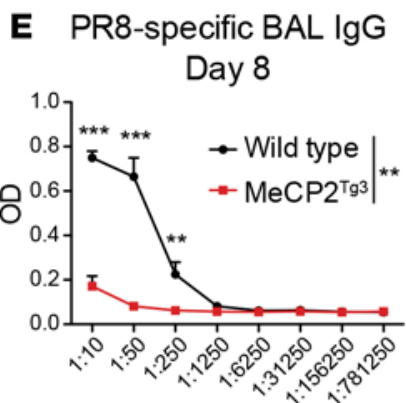

BAL fluid serial dilutions

\section{F PR8-specific BAL IgM} Day 8

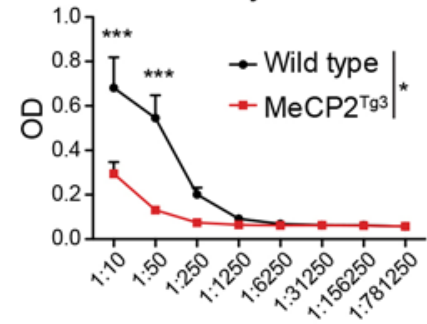

BAL fluid serial dilutions
G BAL Viral Titer Day 8

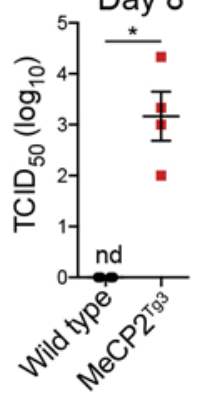

Figure 1. $\mathrm{MeCP2}^{\mathrm{Tg} 3}$ mice are highly susceptible to influenza A infection, with late adaptive immune failure and uncontrolled viral titers. (A) Survival of 12-week-old FVB/C57BL6 F1 male $\mathrm{MeCP} 2^{\mathrm{Tg} 3}$ and wild-type littermates infected with a dose of influenza $A / P R / 8 / 34$ previously determined as $\mathrm{LD}_{100}$ for $\mathrm{MeCP} 2^{\mathrm{Tg} 3}$ mice, representative of greater than 3 experiments. $n=4$ mice per group. ${ }^{*} P=0.0091$ by log-rank (Mantel-Cox) test. (B) Weight loss kinetics as measured by percentage of body weight lost \pm SEM during infection, representative of greater than 3 experiments. (C) Lung immune cell counts \pm SEM as measured by flow cytometry on day 3 post infection (p.i.). $n=3$ mice per group. ${ }^{*} P=0.0225$ by 2 -tailed Student's $t$ test. (D) Lung immune cell counts \pm SEM as measured by flow cytometry on day 8 p.i., representative of 2 experiments. $n$ $=3$ mice per group. ${ }^{*} P<0.05,{ }^{* *} P<0.01$ by 2-tailed Student's $t$ test. (E and $\mathbf{F}$ ) Influenza A/PR/8-specific IgG and IgM antibody titers \pm SEM as measured by ELISA in bronchoalveolar lavage (BAL) fluid from day 8 p.i. $n=3$ mice per group. ${ }^{*} P<0.05,{ }^{* *} P<0.01,{ }^{* *} P<0.001$ by 2-way ANOVA with Bonferroni post test. (G) Viral titers \pm SEM from BAL fluid measured on day 8 p.i. by tissue culture infectious dose $\left(\mathrm{TCID}_{50}\right) . n=4$ mice per group. ${ }^{*} P=0.0211$ by Mann-Whitney test.

to 5-fold above normal, also demonstrate impaired IFN- $\gamma$ levels during infection in vivo (7). This defect in IFN- $\gamma$ production was hypothesized to account for the chronic infections seen in MeCP2 duplication syndrome (7). Importantly, Yang et al. demonstrated that transfer of wildtype $\mathrm{CD}^{+} \mathrm{T}$ cells into $\mathrm{MeCP} 2^{\mathrm{Tg} 3}$ mice decreased footpad swelling and increased IFN- $\gamma$ levels during Leishmania major infection (7), suggesting that $\mathrm{CD}^{+} \mathrm{T}$ cells expressing normal levels of $\mathrm{MeCP} 2$ have

the potential to ameliorate immune pathology in an $\mathrm{MeCP} 2$-overexpressing host.

More recently, defects in antibody production have been implicated in MeCP2 overexpression. In mice, it was shown that MeCP2 overexpression leads to development of anti-nuclear antibodies (18). In patients, deficiency of IgA and $\operatorname{IgG}_{2}$ and excessive levels of $\operatorname{IgG}_{1}$ and $\mathrm{IgG}_{3}$ were found, in addition to an elevated acute-phase response (19). Interestingly, this same study of MeCP2 duplication patients did not detect any obvious $\mathrm{T}$ cell abnormalities, including normal IFN- $\gamma$ production (19).

Here, we demonstrate that $\mathrm{MeCP} 2^{\mathrm{Tg} 3}$ mice are significantly more susceptible to influenza A infection compared with their wild-type counterparts. All $\mathrm{MeCP}^{\mathrm{Tg} 3}$ mice succumbed between days 6 and 9 after infection at a viral dose where the majority of wild-type mice survive. We further demonstrate that although $\mathrm{MeCP}^{\mathrm{Tg} 3}$ mice had an uneventful early response to infection, by day 5 a host of detrimental processes began to be manifested, including increased cytokine production, peripheral and pulmonary neutrophilia, and excessive corticosterone levels. In mice that survived to day 7 or 8 , defective adaptive immune responses were observed with excessive virus accumulation in the lungs. Pharmacologic targeting of neither the increased cytokine production nor the elevated corticosterone was effective in preventing mortality, although some improvement in weight loss was observed. Despite the prevalence of immune defects, bone marrow transplant revealed that replacement of radiosensitive immune cells of the $\mathrm{MeCP} 2^{\mathrm{Tg} 3}$ hematopoietic system 

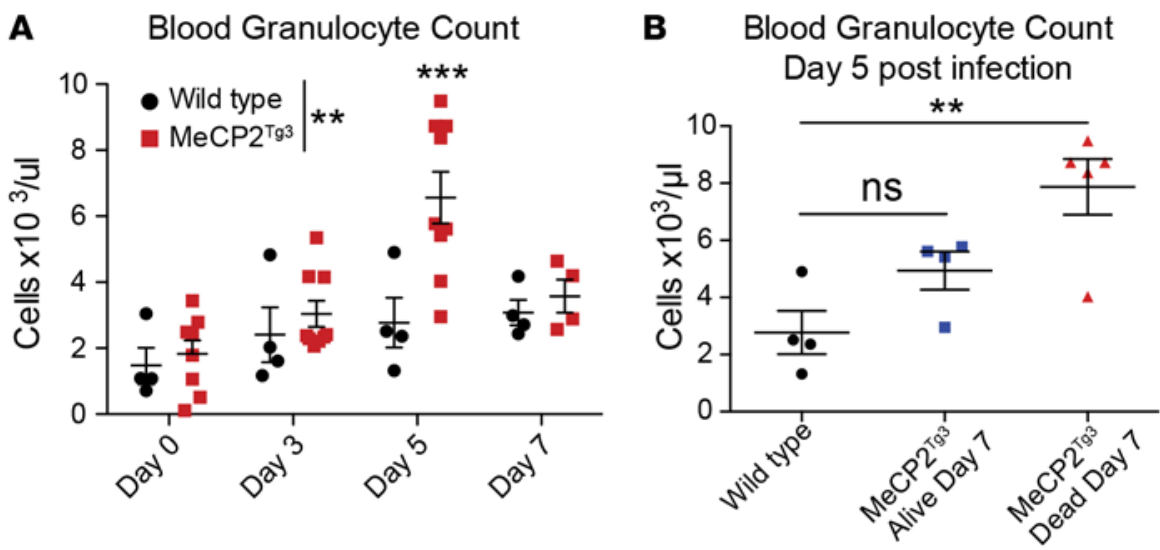

C Blood Neutrophils, Day 5 post infection
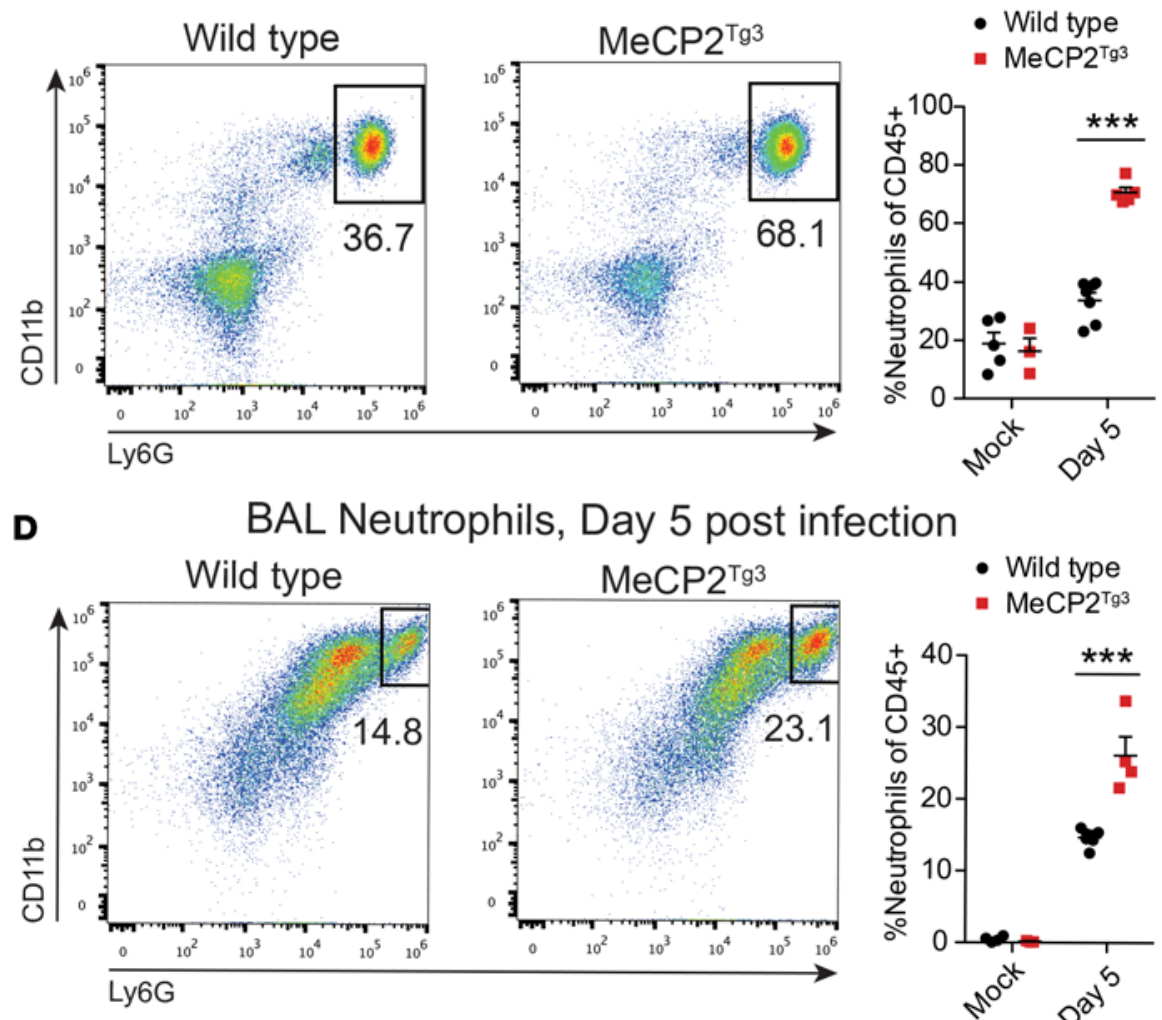

Figure 2. Peripheral and pulmonary neutrophilia associated with mortality occurs on day 5 p.i. in MeCP2 ${ }^{\mathrm{Tg} 3}$ mice. (A) Complete blood count (CBC) granulocyte counts \pm SEM from serial tail blood samples taken on days $0,3,5$, and 7 post infection (p.i.). $n=4$ wild-type and $9 \mathrm{MeCP} 2{ }^{\mathrm{Tg} 3}$ mice. ${ }^{* *} P<0.01$, ${ }^{* * *} P<0.001$ by 2 -way ANOVA with Bonferroni post test. (B) Comparison of granulocyte count \pm SEM on day 5 p.i. between wild-type, $\mathrm{MeCP2}{ }^{\mathrm{Tg} 3}$ mice that succumbed prior to day 7 , and $\mathrm{MeCP} 2^{\mathrm{Tg} 3}$ mice that survived to day $7(n=$ 4,5 , and 4 , respectively). ${ }^{*} P<0.01$ by 1 -way ANOVA with Tukey's multiple comparisons test. (C) Percentage \pm SEM of blood neutrophils out of all live/singlet/CD45+ blood cells on day 5 p.i., representative of 3 experiments. For mock infected, $n=5$ wild type and 3 MeCP2 ${ }^{\top \mathrm{g} 3}$. For day- 5 infected, $n=7$ wild type and $5 \mathrm{MeCP} 2^{\mathrm{Tg} 3}$. ${ }^{* *} P<0.001$ by 2-way ANOVA with Bonferroni post test. (D) Percentage \pm SEM of bronchoalveolar lavage (BAL) neutrophils out of all live/singlet/CD45 $5^{+}$BAL cells on day 5 p.i. For mock infected, $n=5$ wild type and $3 \mathrm{MeCP} 2^{\mathrm{Tg} 3}$. For day-5 infected, $n=7$ wild type and $4 \mathrm{MeCP}^{\mathrm{Tg} 3}$. ${ }^{* *} P<0.001$ by 2 -way ANOVA with Bonferroni post test.

was insufficient to rescue mortality. Further investigation revealed that $\mathrm{MeCP} 2^{\mathrm{Tg} 3}$ mice experience significant vascular pathology during infection, including pulmonary hemorrhage, reduced accumulation of fluid/proteins/cells into the airways by day 7 or 8 , and high pulmonary artery pressure with histologic evidence of pulmonary arterial edema and luminal narrowing. Together, these results suggest that susceptibility to influenza A infection in the context of MeCP2 overexpression may involve pathologic responses of both immune cells and nonhematopoietic cells, and that nonhematopoietic cells may play a key role in infection-related mortality.

\section{Results}

$M e C P 2^{T g 3}$ mice are highly susceptible to influenza $A$ infection, with a normal initial immune response followed by adaptive immune failure. We chose to breed $\mathrm{MeCP} 2^{\mathrm{Tg} 3}$ mice, which are commercially available on the FVB background, on a first generation C57BL6/J $\times$ FVB F1 cross to facilitate the use of genetic tools and reagents available for C57BL6 mice. Importantly, the male $\mathrm{MeCP} 2^{\mathrm{Tg} 3}$ mice used in this study only began to die of natural causes after 200 days, with over $50 \%$ of mice surviving to 1 year (Supplemental Figure 1A; supplemental material available online with this article; doi:10.1172/jci.insight.88257DS1). No defects were observed in the baseline immune status of $\mathrm{MeCP} 2^{\mathrm{Tg} 3}$ mice, as measured by flow cytometry of peripheral blood (Supplemental Figure 1, B-D). Because $\mathrm{MeCP}^{\mathrm{Tg} 3}$ mice did not begin to die of natural causes until approximately 28 weeks of age and appeared healthy for the first several months of life, we performed our experiments in adult $\mathrm{MeCP}^{\mathrm{Tg} 3}$ and wild-type littermates between the ages of 10 and 15 weeks, with most experiments performed at 12 weeks of age.

It was previously demonstrated that $\mathrm{MeCP} 2$-overexpressing mice $\left(\mathrm{MeCP}^{\mathrm{Tg}}{ }^{3}\right)$ and humans exhibit impaired IFN- $\gamma$ production by $\mathrm{Th} 1 \mathrm{CD}^{+} \mathrm{T}$ cells, and this was suggested to be the primary etiology of 


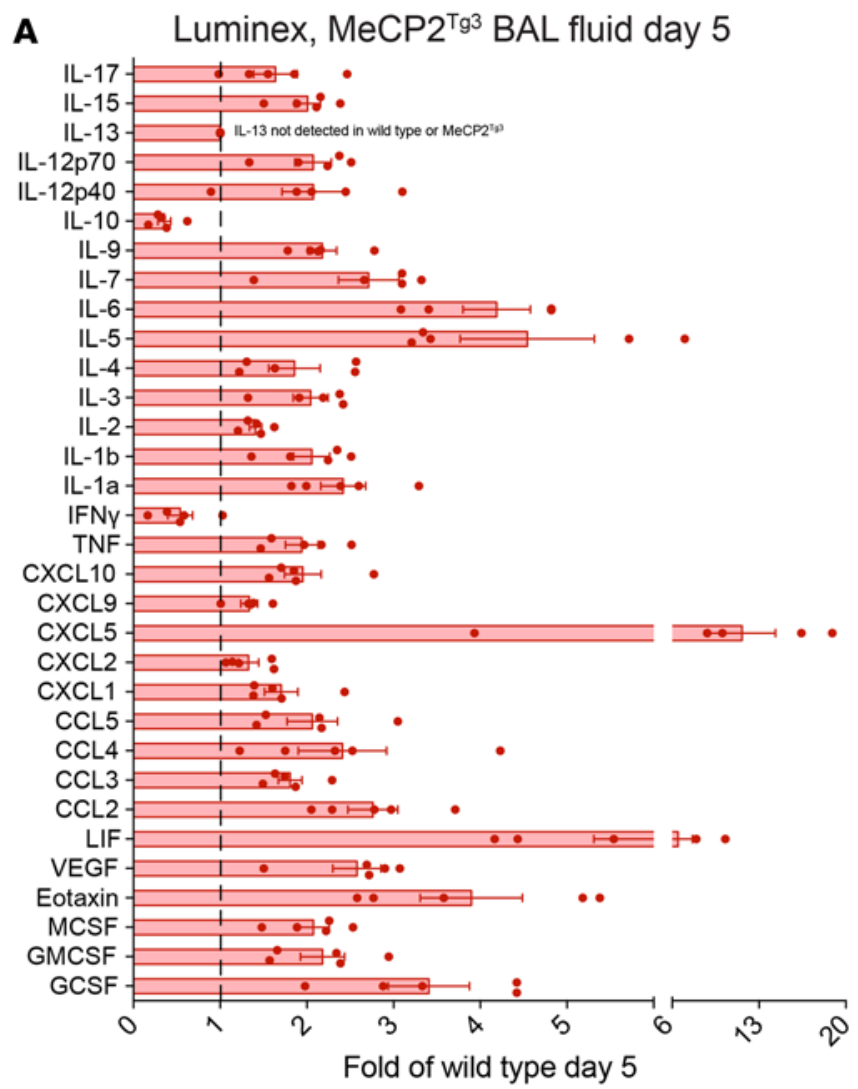

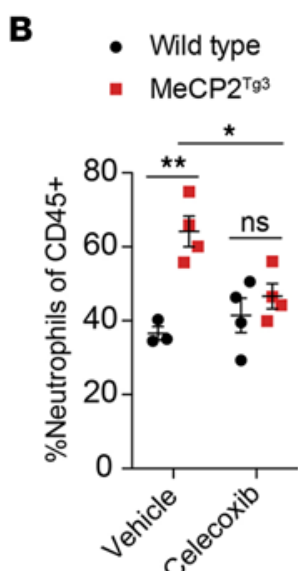

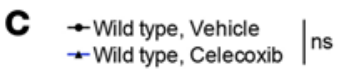
-Wild type, Celecoxib - MeCP2 ${ }^{\mathrm{Tg} 3}$, Vehicle $\rightarrow \mathrm{MeCP} 2^{\mathrm{Tg}}{ }^{3}$, Celecoxib

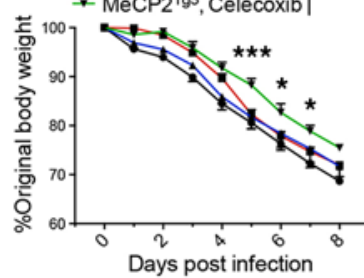

Days post infection

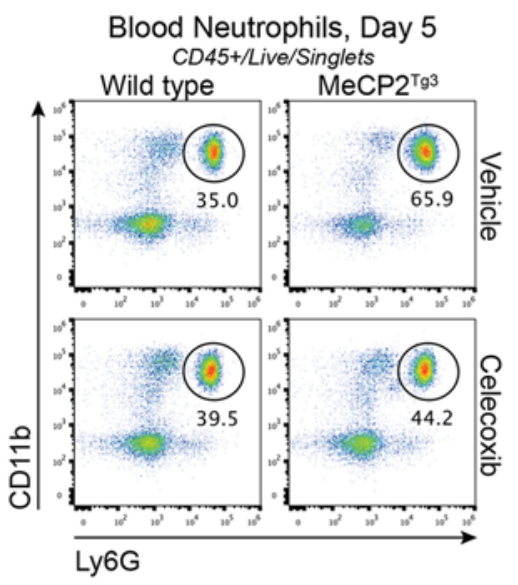

D $\rightarrow$ Wild type, Vehicle $\leftarrow$ Wild type, Celecoxib

$-\mathrm{MeCP} 2^{\mathrm{Tg} 3}$, Vehicle $\rightarrow \mathrm{MeCP} 2^{\mathrm{Tg} 3}$, Celecoxib

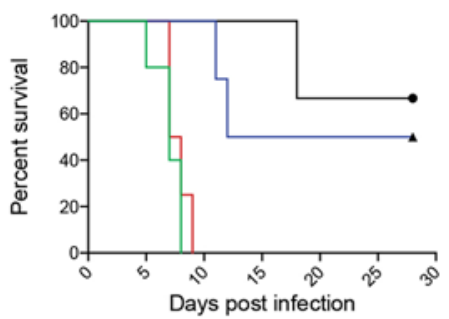

Figure 3. MeCP2 ${ }^{\top 93}$ mice develop increased cytokine production in the lungs, and COX-2 inhibition corrects neutrophilia and reduces weight loss but does not improve survival. (A) Luminex analysis of bronchoalveolar lavage (BAL) fluid from day 5 post infection (p.i.), presented as fold change vs. wild-type protein levels ( $n=5$ mice per group; see Table 1 for statistics). (B) Blood neutrophil percentage \pm SEM out of all live/singlet/CD45 cells on day 5 p.i. after daily $25 \mathrm{mg} / \mathrm{kg}$ celecoxib or vehicle treatment. For vehicle treated, $n=3$ wild type and $4 \mathrm{MeCP} 2^{\text {Tg3 }}$. For celecoxib treated, $n=4$ wild type and $4 \mathrm{MeCP} 2 \mathrm{~T}^{\mathrm{T} 3} .{ }^{*} \mathrm{P}<0.05,{ }^{*} \mathrm{P}<0.01$ by 2 -way ANOVA with Bonferroni post test. $\mathrm{ns}$, not significant. (C) Weight loss kinetics $\pm \mathrm{SEM}$ during infection with $25 \mathrm{mg} / \mathrm{kg}$ celecoxib treatment, representative of 2 experiments. For vehicle treated, $n=3$ wild type and $4 \mathrm{MeCP} 2^{\mathrm{Tg} 3}$. For celecoxib treated, $n=4$ wild type and $5 \mathrm{MeCP2} 2{ }^{\mathrm{Tg} 3}$. ${ }^{*} P<0.05$, ${ }^{* *} P<0.001$ by 2 -way ANOVA with Bonferroni post test. (D) Influenza A/PR/8/34 survival with $25 \mathrm{mg} / \mathrm{kg}$ celecoxib or vehicle treatment, representative of 2 experiments. For vehicle treated, $n=3$ wild type and $4 \mathrm{MeCP}^{\text {Tg }}{ }^{3}$. For celecoxib treated, $n=4$ wild type and $5 \mathrm{MeCP}^{\mathrm{Tg} 3}$. Log-rank (Mantel-Cox) test, not significant.

chronic infection in $\mathrm{MeCP} 2$ duplication syndrome patients (7). However, it has also been shown that IFN- $\gamma$-null mice are able to effectively respond to, and clear, primary influenza A infection (20). Thus, we hypothesized that if IFN- $\gamma$ accounts for the major immune deficit in MeCP2 ${ }^{\mathrm{Tg} 3}$ mice, they should effectively clear primary influenza A infection. Surprisingly, $\mathrm{MeCP}^{\mathrm{Tg} 3}$ mice infected at 12 weeks of age universally succumbed to infection approximately 6-9 days post infection (p.i.), demonstrating significantly increased mortality as compared with wild-type mice infected with the same dose of virus (Figure 1A). The percentage of body weight loss was similar between $\mathrm{MeCP} 2^{\mathrm{Tg} 3}$ and wild-type mice (Figure 1B).

Analysis of the host response in the lungs on day 3 p.i. revealed that immune cell counts were overall comparable between $\mathrm{MeCP} 2^{\operatorname{Tg} 3}$ and wild-type mice (Figure $1 \mathrm{C}$ ). This is a time when the innate immune cells have entered the lungs in response to infection but prior to the onset of the adaptive immune response in the lungs, i.e., when the adaptive response is being initiated in the lung-draining lymph nodes. In order to assess the ability of $\mathrm{MeCP}^{\mathrm{Tg} 3} \mathrm{~T}$ cells to mount an antigen-specific $\mathrm{CD} 8^{+} \mathrm{T}$ cell response, we crossed $\mathrm{MeCP} 2^{\mathrm{Tg} 3}$ mice with $\mathrm{T}$ cell receptor (TCR) transgenic OTI mice to produce $\mathrm{MeCP}^{\mathrm{Tg} 3}:: \mathrm{OTI}^{+/-}$and wild-type::OTI ${ }^{+/-}$ littermates. OTI mice express, on CD8 ${ }^{+} \mathrm{T}$ cells, a transgenic TCR specific for chicken ovalbumin (OVA) (21), and thus these $\mathrm{T}$ cells can be used to assess antigen-specific $\mathrm{CD} 8^{+} \mathrm{T}$ cell responses to the OVA antigen. In order to assess the antigen-specific $\mathrm{CD}^{+} \mathrm{T}$ cell response in the context of influenza infection, 2 million wildtype or $\mathrm{MeCP}^{\mathrm{Tg} 3}$ ::OTI T cells were transferred into wild-type or $\mathrm{MeCP}^{\mathrm{Tg} 3}$ hosts. Twenty-four hours following $\mathrm{T}$ cell transfer, mice were infected with influenza A/PR/8 virus engineered to express the OVA epitope recognized by OTI $\mathrm{T}$ cells, and the antigen-specific $\mathrm{T}$ cell response in the draining mediastinal lymph node 
Table 1. Luminex analysis of bronchoalveolar lavage (BAL) fluid in wild-type and $\mathrm{MeCP}^{\mathrm{Tg}}{ }^{3}$ mice

\begin{tabular}{|c|c|c|c|}
\hline \multicolumn{4}{|c|}{ Luminex of BAL fluid, day 5 after infection } \\
\hline \multirow[b]{2}{*}{ Molecule } & \multicolumn{2}{|c|}{ Concentration $(\mathrm{pg} / \mathrm{ml} \pm$ SEM) } & \multirow[b]{2}{*}{$P$ value } \\
\hline & Wild type & $\mathrm{MeCP} 2^{\text {Tg3 }}$ & \\
\hline IL-17 & $1.606 \pm 0.2453$ & $2.630 \pm 0.4033$ & 0.0619 \\
\hline IL-15 & $21.55 \pm 1.742$ & $43.26 \pm 3.210$ & 0.0003 \\
\hline IL-13 & Not detected & Not detected & N/A \\
\hline IL-12p70 & $5.366 \pm 0.5995$ & $11.12 \pm 1.127$ & 0.002 \\
\hline IL-12p40 & $3.412 \pm 0.5398$ & $7.082 \pm 1.236$ & 0.0262 \\
\hline IL-10 & $39.68 \pm 19.36$ & $14.14 \pm 2.959$ & 0.2285 \\
\hline IL-9 & $72.20 \pm 7.842$ & $157.2 \pm 11.89$ & 0.0003 \\
\hline IL-7 & $0.4960 \pm 0.1437$ & $1.682 \pm 0.2160$ & 0.0018 \\
\hline IL-6 & $2058 \pm 186.2$ & $8623 \pm 800.1$ & $<0.0001$ \\
\hline IL-5 & $28.78 \pm 5.473$ & $130.7 \pm 22.27$ & 0.0022 \\
\hline IL-4 & $0.9500 \pm 0.2524$ & $1.764 \pm 0.2816$ & 0.0635 \\
\hline IL-3 & $1.778 \pm 0.2475$ & $3.634 \pm 0.3583$ & 0.0028 \\
\hline IL-2 & $3.292 \pm 0.2591$ & $4.634 \pm 0.2328$ & 0.0049 \\
\hline IL-1 $\beta$ & $21.70 \pm 2.000$ & $44.59 \pm 4.538$ & 0.0017 \\
\hline IL-1 $\alpha$ & $10.82 \pm 2.318$ & $26.18 \pm 2.795$ & 0.0029 \\
\hline $\mathrm{IFN}-\gamma$ & $996.6 \pm 477.5$ & $538.4 \pm 141.8$ & 0.3845 \\
\hline TNF- $\alpha$ & $37.81 \pm 2.808$ & $73.43 \pm 7.207$ & 0.0017 \\
\hline CXCL10 & $2770 \pm 405.6$ & $5412 \pm 587.7$ & 0.006 \\
\hline CXCL9 & $2610 \pm 628.5$ & $3485 \pm 250.8$ & 0.2318 \\
\hline CXCL5 & $4.808 \pm 1.805$ & $55.90 \pm 12.97$ & 0.0045 \\
\hline CXCL2 & $131.1 \pm 3.970$ & $174.1 \pm 15.35$ & 0.0267 \\
\hline CXCL1 & $804.9 \pm 60.80$ & $1372 \pm 155.4$ & 0.0094 \\
\hline CCL5 & $48.91 \pm 3.036$ & $100.9 \pm 14.23$ & 0.0073 \\
\hline CCL4 & $643.9 \pm 87.99$ & $1552 \pm 327.5$ & 0.028 \\
\hline CCL3 & $225.2 \pm 12.51$ & $406.9 \pm 30.69$ & 0.0006 \\
\hline CCL2 & $1451 \pm 199.0$ & $4007 \pm 419.2$ & 0.0006 \\
\hline LIF & $182.2 \pm 9.589$ & $1179 \pm 211.6$ & 0.0015 \\
\hline VEGF & $21.99 \pm 5.641$ & $56.67 \pm 6.091$ & 0.0031 \\
\hline Eotaxin & $125.4 \pm 16.57$ & $488.8 \pm 73.97$ & 0.0014 \\
\hline MCSF & $19.48 \pm 1.389$ & $40.43 \pm 3.524$ & 0.0006 \\
\hline GMCSF & $50.18 \pm 5.760$ & $109.4 \pm 12.78$ & 0.0029 \\
\hline GCSF & $1606 \pm 140.2$ & $5473 \pm 752.1$ & 0.001 \\
\hline
\end{tabular}

BAL fluid from wild-type and MeCP2 $2^{\top 93}$ mice on day 5 after infection with influenza $A / P R / 8 / 34$ was assessed for cytokine, chemokine, and growth factor levels. Values are displayed as $\mathrm{pg} / \mathrm{ml} \pm$ SEM. Two-tailed Student's $t$ test was performed for statistical analyses, $n=5$ mice per group. was assessed on day 3.5 p.i. We found that there was no difference in $\mathrm{T}$ cell proliferation based on genotype of the $\mathrm{T}$ cells; however, MeCP2 ${ }^{\mathrm{Tg} 3}$ hosts actually had an increased number of OTI T cells and increased proliferation of OTI T cells on day 3.5 (Supplemental Figure 2, A-C), suggesting that host genotype, rather than $\mathrm{T}$ cell genotype, may be driving any differences in influenza A response.

Although we found increased antigen-specific OTI $\mathrm{T}$ cell proliferation in $\mathrm{MeCP} 2^{\mathrm{Tg} 3}$ hosts on day 3.5, we were surprised to find that the entire adaptive immune cell and antibody compliment in the lungs appeared to be blunted by day 8 p.i. T and $B$ cell numbers in the $\mathrm{MeCP} 2^{\mathrm{Tg} 3}$ lung parenchyma were reduced, while innate immune cell numbers were normal or elevated at day 8 (Figure 1D and Supplemental Figure 2D). Influenza Aspecific antibody titers were greatly reduced in bronchoalveolar lavage (BAL) fluid (Figure 1, E and F), and influenza A viral titers were significantly elevated above wild type, in which no virus was detectable on day 8 (Figure 1G). In addition to the reduced overall number of $\mathrm{T}$ cells, there was also a decreased percentage of influenza A-specific $\mathrm{CD}^{+} \mathrm{T}$ cells among total $\mathrm{CD}^{+} \mathrm{T}$ cells as measured by nucleoprotein (NP) and polymerase acidic protein (PA) tetramer staining (Supplemental Figure $2 \mathrm{E}$ ). In agreement with this finding and previously published data (7), we found that both $\mathrm{CD}^{+}$and $\mathrm{CD} 8^{+} \mathrm{MeCP} 2^{\mathrm{Tg} 3} \mathrm{~T}$ cells exhibited significantly reduced IFN- $\gamma$ production upon restimulation by influenza A virus-loaded bone marrow-derived dendritic cells (BMDCs), with minimal differences based on the genotype of BMDC used as antigen-presenting cells (APCs), i.e., wild-type or $\mathrm{MeCP}^{\mathrm{Tg} 3}$ bone marrow origin (Supplemental Figure 2, F and G). Therefore, there was both a reduced percentage of IFN- $\gamma$-producing $\mathrm{T}$ cells and reduced overall T cell numbers, which likely combine to explain IFN- $\gamma$ deficiency observed in the context of MeCP2 overexpression. Although this finding is consistent with previously published data (7), IFN- $\gamma$-null mice have been shown to clear and survive primary influenza A virus infection (20); therefore, it is unlikely that this explained the death of these mice following influenza A infection.

Influenza $A$ infection of $M e C P 2^{T g 3}$ mice results in severe lung pathology by 5 days p.i. Because the innate immune response appeared normal in these mice at day 3 p.i., but the adaptive response in the lungs was defective at day 8 , we decided to perform serial complete blood count $(\mathrm{CBC})$ measurements on peripheral blood to detect any obvious global changes occurring during the course of infection. These data revealed a robust and specific increase in granulocytes on day 5 p.i. (Figure 2A). Interestingly, those mice that succumbed prior to blood collection on day 7 had a significantly elevated granulocyte count at day 5 p.i., while those that survived to day 7 did not have significantly elevated granulocyte counts on day 5 (Figure 2B). Flow cytometric analysis of peripheral blood and BAL fluid on day 5 demonstrated that neutrophils were significantly elevated in both compartments (Figure 2, C and D). This widespread neutrophilia suggested global exacerbation of innate inflammation in $\mathrm{MeCP} 2^{\mathrm{Tg} 3}$ mice on day 5 p.i., that is, prior to the onset of the adaptive response in the infected lungs. In agreement with this, Luminex analysis of day 5 BAL fluid revealed a widespread increase in inflammatory cytokines and chemokines (Figure 3A and Table 1), consistent with infectioninduced excess cytokine production and enhanced pulmonary injury (22). Accordingly, we attempted to reduce inflammation via the use of the COX-2-specific inhibitor, celecoxib. Daily celecoxib treatment normalized neutrophil levels (Figure 3B), and weight loss was attenuated (Figure 3C) without any effect 
on survival (Figure 3D). Importantly, there was no difference in weight loss (Figure 3C) or neutrophil levels (Figure $3 \mathrm{~B}$ ) after celecoxib treatment in wild-type mice, demonstrating a specific role for excessive inflammation in $\mathrm{MeCP}^{\mathrm{Tg} 3}$ mice.

Previous reports have implicated $\mathrm{MeCP} 2$ in the control of glucocorticoid response $(13,23,24)$. In addition, MeCP2-overexpressing mice have been shown to have an enhanced response to stress (25). Therefore, we measured serum corticosterone levels during infection, and found a significant increase starting on day 5 and persisting through day 8 (Supplemental Figure 3A). Importantly, glucocorticoids are potent inhibitors of both $\mathrm{T}$ and $\mathrm{B}$ cells (26), and could explain adaptive immune suppression observed between day 3 and 8 . However, similar to celecoxib treatment, treatment with either the glucocorticoid inhibitor mifepristone or combination treatment with mifepristone and celecoxib resulted in attenuated weight loss (Supplemental Figure 3B), but with no effect on $\mathrm{MeCP}^{\mathrm{Tg} 3}$ survival after influenza A infection (Supplemental Figure 3C). These results suggest that glucocorticoids play a role in the pathology observed in $\mathrm{MeCP} 2^{\mathrm{Tg} 3}$ mice exposed to influenza A virus, but are insufficient to explain the full extent of disease.

Radioresistant cells are essential for influenza A-induced mortality in $M e C P 2^{T g 3}$ mice. Based on these cumulative results, we questioned the overall role of hematopoietic cells in explaining influenza A-induced mortality in $\mathrm{MeCP}^{\mathrm{Tg} 3}$ mice. Towards this end, we transplanted wild-type or $\mathrm{MeCP} 2^{\mathrm{Tg} 3}$ mice with either wildtype or $\mathrm{MeCP}^{\mathrm{Tg} 3}$ bone marrow and infected with influenza $\mathrm{A} / \mathrm{PR} / 8 / 34$. Survival was not improved by wild-type bone marrow, nor was survival impaired by $\mathrm{MeCP} 2^{\mathrm{Tg} 3}$ bone marrow, regardless of host genotype (Figure 4A). This strongly suggests that radiosensitive cells of the immune system alone do not account for mortality in $\mathrm{MeCP} 2^{\mathrm{Tg} 3}$ mice, because the $\mathrm{MeCP} 2^{\mathrm{Tg} 3}$ immune system was insufficient to cause death in wild-type hosts, and a wild-type immune system was unable to rescue survival in $\mathrm{MeCP} 2^{\mathrm{Tg} 3}$ hosts. Thus, we concluded that radioresistant cells must play an essential role in mortality upon influenza A infection in $\mathrm{MeCP} 2^{\mathrm{Tg} 3}$ mice.

We had previously noted that BAL fluid from infected $\mathrm{MeCP} 2^{\mathrm{Tg} 3}$ mice was bloody, suggesting increased vascular leakage. When we measured BAL red blood cell $(\mathrm{RBC})$ numbers via flow cytometry on day 5 p.i., we found significantly more RBCs in BAL fluid of infected $\mathrm{MeCP} 2^{\mathrm{Tg} 3}$ mice (Figure 4B). In agreement with these findings, we observed that $\mathrm{MeCP} 2^{\operatorname{Tg} 3}$ lungs appeared grossly erythematous on day 7 (Figure 4C). Analysis of BAL fluid from uninfected, day 5, and day 7 p.i. $\mathrm{MeCP}^{\mathrm{Tg} 3}$ mice revealed a progressive increase in airway hemorrhage. By contrast, there was no blood evident in BAL fluid from infected wildtype mice (Figure 4D). As an additional measure of vascular leakage, Evans Blue dye accumulation was measured in the BAL fluid of infected mice 1 hour after i.p. dye injection. Interestingly, while wild-type mice demonstrated Evans Blue in their airways only on day 7 (as would be expected with increasing pulmonary inflammation), some $\mathrm{MeCP} 2^{\mathrm{Tg} 3}$ mice had Evans Blue in their airway starting on day 5 , but had significantly less than wild type by day 7 (Figure 4D). This suggested that although airway hemorrhage was occurring on day 5, transport of protein/fluid from the vasculature to the airways was impaired by day 7 p.i. In agreement with this finding, on day $7 \mathrm{MeCP}^{\mathrm{Tg} 3}$ lungs displayed marked areas of vascular congestion even after pulmonary vascular perfusion with PBS (Figure 4E). We also found that, in contrast with results on day 3 p.i., the number of infiltrating airway cells was significantly reduced in $\mathrm{MeCP} 2^{\mathrm{Tg} 3} \mathrm{BAL}$ fluid on day 8 (Figure $4 \mathrm{~F}$ ), again supporting the possibility that access to the pulmonary vascular compartment is compromised in $\mathrm{MeCP} 2^{\mathrm{Tg} 3}$ mice after day 5 of infection.

Histological analysis of lungs from mice day 7 p.i. revealed capillary congestion and alveolar hemorrhage, likely reflecting damage occurring on and after day 5 p.i. (Supplemental Figure 4A). Importantly, overall tissue integrity as detected by histology was comparable between wild-type and $\mathrm{MeCP} 2^{\mathrm{Tg} 3}$ mice, suggesting that the observed vascular defects represented the major tissue damage leading to death upon infection in $\mathrm{MeCP} 2^{\mathrm{Tg} 3}$ mice. Because we had observed defects in pulmonary perfusion, we decided to measure pulmonary function, which includes pulmonary artery pressure. While resistance and compliance were similar to that of wild type (as expected, since no increased tissue destruction was evident in $\mathrm{H} \& \mathrm{E}$ staining), pulmonary artery pressure was significantly elevated in $\mathrm{MeCP} 2^{\mathrm{Tg} 3}$ mice on day 8 (Figure $4 \mathrm{G}$ ). H\&E analysis revealed both perivascular edema and pulmonary arterial narrowing in $\mathrm{MeCP} 2^{\mathrm{Tg} 3}$ mice (Figure $4 \mathrm{H}$ and Supplemental Figure 4B), consistent with pulmonary arterial hypertension (Figure $4 \mathrm{G}$ ) and inability to effectively perfuse the infected $\mathrm{MeCP} 2^{\mathrm{Tg} 3}$ lungs (Figure $4 \mathrm{E}$ ). In sum, these data suggest that $\mathrm{MeCP} 2^{\mathrm{Tg} 3}$ mice experience pulmonary hemorrhage starting on day 5 , with subsequent high pulmonary artery pressure and arterial narrowing, which may ultimately contribute to infection-related mortality. 


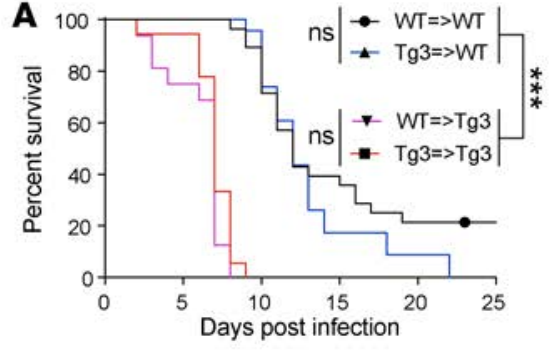

D
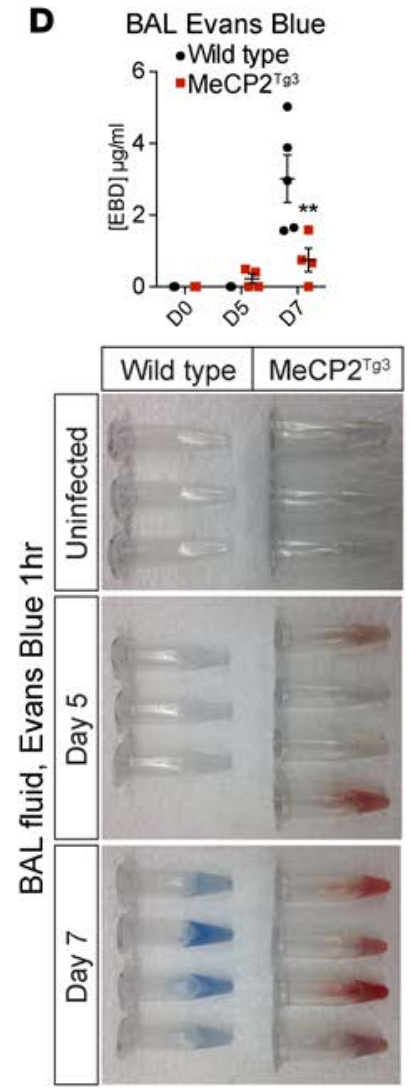

B

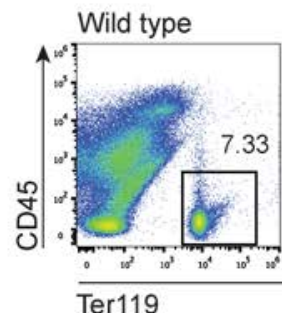

E

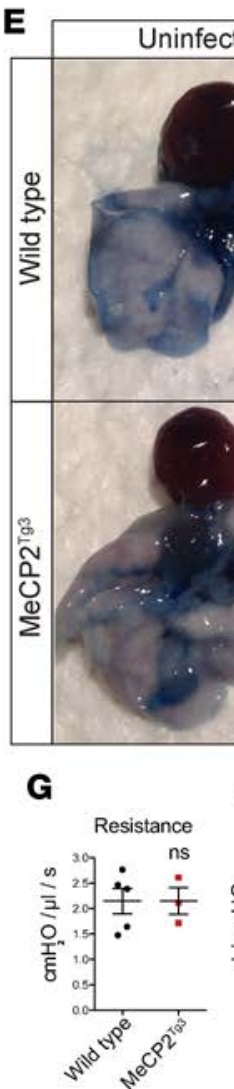

BAL RBCs, Day 5 post infection

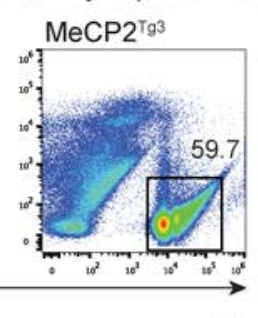

$\mathbf{F}$

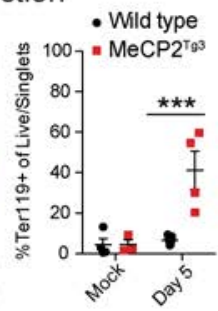

F BAL Cell Count - Wild type $\mid$ MeCP2 $2^{\top \beta^{3}} \mid * \star$

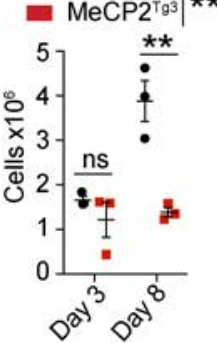

C

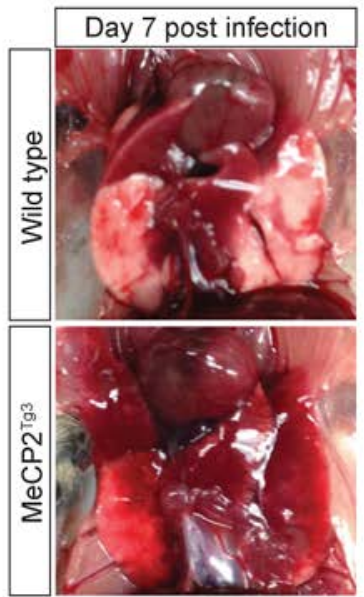

Figure 4. Bone marrow transplant does not induce or rescue mortality, and influenza $\mathbf{A}$ infection in MeCP2 ${ }^{\mathrm{Tg} 3}$ mice leads to vascular pathology. (A) Survival curve for mice infected with influenza A/PR/8/34 that were given bone marrow transplant with MeCP2 ${ }^{\text {Tg3 }}$ or wild-type bone marrow. $n=28$ for WT $\rightarrow$ WT, $n=23$ for Tg3 $\rightarrow$ WT, $n=16$ for WT $\rightarrow$ Tg3, and $n=18$ for Tg3 $\rightarrow$ Tg3. ${ }^{* * *} P<0.001$ by log-rank (Mantel-Cox) test. ns, not significant. (B) Flow cytometry of RBCs in bronchoalveolar lavage (BAL) fluid on day 5 post infection (p.i.). Mock infected, $n=4$ wild type and 3 MeCP2 ${ }^{\text {Tg3 }}$. Day- 5 infected, $n=7$ wild type and $4 \mathrm{MeCP} 2^{\mathrm{Tg} 3}$. Quantification on right shows percentage of cells expressing the erythroid marker Ter119 (mean \pm SEM). ${ }^{* *} P<0.001$ by 2 -way $A N 0 V A$ with Bonferroni post test. (C) Gross appearance of wild-type and MeCP2 ${ }^{\mathrm{Tg} 3}$ lungs on day 7 p.i. (D) Images and quantification of Evans Blue dye (EBD) in BAL fluid taken from uninfected, day 5 p.i., and day 7 p.i. Mice were injected with EBD 1 hour prior to harvest. For day $0, n=3$ wild type and 3 MeCP2 ${ }^{\text {Tg3 }}$. For day- 5 infected, $n=3$ wild type and 4 MeCP2 ${ }^{\text {Tg3 }}$. For day-7 infected, $n=5$ wild type and 4 MeCP2 ${ }^{\text {Tg3 }}$. Mean \pm SEM. ${ }^{*} P<0.01$ by 2 -way ANOVA with Bonferroni post test. (E) Gross appearance of lungs from mice given EBD and analyzed 1 hour later. Lungs were perfused to remove remaining vascular dye and blood, and BAL fluid was taken. Images are representative of $n=3$ mice per group for uninfected, and $n=4$ mice per group for day 7 p.i. (F) Total BAL cell counts (mean \pm SEM) on day 3 and day 8 p.i. $n=3$ mice per group. ${ }^{*} P<0.01$ by 2 -way ANOVA with Bonferroni post test. ns, not significant. (C) Resistance, compliance, and pulmonary artery pressure measured on day 8 p.i. $n=5$ for wild type and 3 for MeCP2 ${ }^{\text {Tg3}} ;$ mean \pm SEM. ${ }^{* *} P=0.0074$ by 2 -tailed Student's $t$ test. (H) H\&E staining of day 7 p.i. lungs that were not perfused or inflated demonstrates both arterial narrowing and perivascular edema (black arrowheads, pulmonary arteries). Representative of 2 experiments with at least $n=3$ mice per group. Scale bar: $200 \mu \mathrm{m}$ for large images, and $50 \mu \mathrm{m}$ for insets.

\section{Discussion}

Here we demonstrated that influenza A infection in MeCP2-overexpressing mice results initially (up to day 3 p.i.) in a normal immune response, but abnormally progresses into excessive innate inflammation, high corticosterone levels, defective adaptive immunity, uncontrolled virus replication, vascular defects, and death approximately 6-9 days p.i. Most pathologic findings began on day 5 p.i., indicating this as a critical turning point. Much of our data regarding adaptive immune system function agrees with previous 
reports $(7,18,19)$, and suggests that the adaptive immune response is markedly impaired in the context of $\mathrm{MeCP} 2$ overexpression. We have also identified multiple other pathologic processes during infection in $\mathrm{MeCP} 2^{\mathrm{Tg} 3}$ mice, suggesting that the impairment of the adaptive immune response is just one of a complex set of abnormalities occurring during infection in the context of $\mathrm{MeCP} 2$ overexpression.

In addition to defects in immune cells, radioresistant cells were also essential to infection-associated lethality. Bone marrow transplant revealed no effect of immune system genotype on mortality, and substantial vascular impairment (including perivascular edema, pulmonary arterial hypertension, impaired perfusion, and alveolar hemorrhage) was observed in $\mathrm{MeCP} 2^{\mathrm{Tg} 3}$ mice. These results suggest that either direct response of vasculature, or upstream response by other nonhematopoietic cells, may play an important role in disease pathogenesis. In order to identify which cell type(s) are responsible for susceptibility to respiratory infection in $\mathrm{MeCP} 2$-overexpressing mice, it would be necessary to either overexpress or correct $\mathrm{MeCP} 2$ expression levels in specific nonhematopoietic cell types. Unfortunately, such genetic tools to target specific cell types do not currently exist.

Alternatively, radioresistant immune cells, such as tissue-resident macrophages and innate lymphoid cells, may still be playing a key role in pathology. In particular, alveolar macrophages may contribute to the abnormal responses observed here, as these cells are relatively radioresistant compared with circulating immune cells (27). Alveolar macrophages are essential for effective response to and protection from influenza infection (28-30), and we have previously demonstrated that Mecp2 regulates macrophage response to multiple stimuli, including inflammation and glucocorticoids (13), 2 stimuli that are critical in the context of influenza infection. In addition, several groups have demonstrated abnormal inflammatory and glucocorticoid responses with either MeCP2 loss or gain of function in multiple cell types and contexts $(7,10,12,19,23-25,31,32)$. In this study, both abnormal inflammation and excessive glucocorticoid levels were observed, lending support to the possibility that these pathways are disrupted in the context of $\mathrm{MeCP} 2$ overexpression. Future work should endeavor to both create and utilize cell-specific tools to better understand which pulmonary cell types are critical to mortality associated with respiratory infection in the context of MeCP2 overexpression.

The excessive innate inflammation seen in this study may correlate to excessive acute-phase responses observed in MeCP2 duplication syndrome patients (19), and could represent a common defect in the immune response when MeCP2 is overexpressed. Interestingly, significant levels of CXCL5 were observed in $\mathrm{MeCP} 2^{\mathrm{Tg} 3} \mathrm{BAL}$ fluid (Table 1), whereas wild-type mice had little to no CXCL5, potentially implicating respiratory epithelial cells in inflammation as these cells are the major known producers of CXCL5 in the lung (33-36). Although inhibition of innate inflammation did not improve survival, we did see partial improvement in the form of normalized neutrophil levels and attenuated weight loss. It is therefore possible that excessive innate inflammation represents a significant cause of morbidity in $\mathrm{MeCP} 2$ duplication syndrome, and should be investigated as a potential target for amelioration of symptoms during infection in these patients. This may be of particular interest in the context of less severe infections, where symptomatic treatment may be the most salient consideration.

It was previously shown that $\mathrm{MeCP} 2$-overexpressing mice have increased corticosterone release after stress (25), and multiple groups have directly linked MeCP2 to glucocorticoid response $(13,23,24)$, which may explain the increased corticosterone we observed during influenza infection in $\mathrm{MeCP} 2^{\mathrm{Tg} 3}$ mice. In addition, glucocorticoids can suppress the function of and cause apoptosis in lymphocytes (26), potentially helping to explain the deficiency and impairment of lymphocytes seen late during infection. However, glucocorticoids have a complex effect during infection, as they can impair the adaptive immune response but also help control innate inflammation. Thus, pharmacologic intervention may be equally complex, as excessive innate inflammation seen in the context of MeCP2 overexpression may be exacerbated by glucocorticoid blockade. Regardless, the role of $\mathrm{MeCP} 2$ in the glucocorticoid response continues to be an outstanding unresolved question that warrants further investigation.

It is interesting to note that we did measure increased numbers of antigen-specific $\mathrm{CD} 8^{+} \mathrm{T}$ cells in the mediastinal lymph node on day 3.5 p.i., regardless of $\mathrm{T}$ cell genotype. It may be that there is an overactive $\mathrm{T}$ cell priming environment in $\mathrm{MeCP} 2^{\mathrm{Tg} 3}$ mice, potentially due to abnormal APC activity or increased viral load, leading to increased $\mathrm{T}$ cell expansion. The ultimate failure of these $\mathrm{T}$ cells to traffic to the lungs later during infection is not fully understood based on our findings; however, the inhibitory effect of excessive glucocorticoids early during infection may play a role. Alternatively, vascular defects may prevent $\mathrm{T}$ cell trafficking by impairment of vascular access to the pulmonary tissue. Indeed, given our results demonstrating 
hemorrhage, impaired perfusion, and arterial narrowing, this hypothesis may deserve additional investigation in the future. In essence, perhaps the immune system cannot fight infection owing to breakdown of vascular access and subsequent uncontrolled viral replication. Although $\mathrm{T}$ cell-extrinsic mechanisms may explain these defects, as outlined above, it is still important to note that we did in fact measure significantly decreased IFN- $\gamma$ production upon influenza-loaded-BMDC stimulation in both $\mathrm{CD}^{+}$and $\mathrm{CD}^{+} \mathrm{T}$ cells taken from infected $\mathrm{MeCP}^{\mathrm{Tg} 3}$ lungs. While this could be explained by differences in $\mathrm{T}$ cell activation and trafficking, it does not on its own contradict the previous finding that $\mathrm{MeCP} 2^{\mathrm{Tg} 3} \mathrm{CD} 4^{+} \mathrm{T}$ cells are intrinsically impaired in IFN- $\gamma$ production (7). However, our findings do suggest that IFN- $\gamma$ deficiency is unlikely to explain the entirety of respiratory pathology in $\mathrm{MeCP} 2$ duplication syndrome.

Another potential point of future investigation is the role of type I and III interferons, which have been well established as playing a role in controlling influenza virus infection, especially in epithelial cells (37). It is therefore possible that a failure to either produce or signal through type I and/or III interferon pathways in $\mathrm{MeCP} 2^{\mathrm{Tg} 3}$ mice may contribute to failure to control viral infection, which might explain the role of radioresistant cells in mortality.

Our findings could inform future work on respiratory infections in MeCP2 duplication syndrome by suggesting that some potential therapies focusing only on the hematopoietic system, such as bone marrow transplant, may not be viable. Treatment of respiratory infection in MeCP2 duplication syndrome may require therapies either targeting or genetically correcting nonhematopoietic cells. It was recently shown that antisense oligonucleotides can effectively knock down MeCP2 expression in MeCP2-overexpressing mice, and ameliorates neurologic symptoms (38). A similar strategy could be employed in the context of infection in order to correct nonhematopoietic defects. Such an approach may represent the most promising therapy for MeCP2 duplication patients, given our results demonstrating the potential importance of nonhematopoietic cells in the context of infection.

In sum, this work provides evidence that influenza A infection-related morbidity and mortality in the context of $\mathrm{MeCP} 2$ overexpression is a complex process involving defects in both immune and nonhematopoietic cells. Future studies should endeavor to further understand which cell types drive mortality upon respiratory infection in the context of $\mathrm{MeCP} 2$ overexpression, which may lead to targeted therapies for these patients.

\section{Methods}

Mice and infections. FVB-Tg(MECP2)3Hzo/J (Jackson Labs stock 008680), C57BL/6J (Jackson Labs stock 000664), C57BL/6-Tg(UBC-GFP)30Scha/J (Jackson Labs stock 004353), and B6.129S7-Rag 1 ${ }^{\text {tmlMom }}$ $\mathrm{Tg}$ (TcraTcrb)1100Mjb (Taconic) were maintained by in-house breeding. The background strain for all mice used in experiments was first-generation F1 C57BL6 $\times$ FVB $\left(\mathrm{MeCP}^{\mathrm{Tg} 3}\right.$ female on FVB background bred with C57BL6 background male) to allow for use of transgenes only available on the C57BL6 background. The $\mathrm{MeCP} 2^{\mathrm{Tg} 3}$ mice contain a human MeCP2 transgene on the $\mathrm{X}$ chromosome. Female mice are hemizygous for the transgene, and therefore $50 \%$ of male offspring will receive a copy of the transgene. Mice used for infection experiments were all male to most closely mimic the human disease, and were typically 12 weeks of age, with a range of 10 to 15 weeks, and were age matched within each experiment. Mice were anesthetized via i.p. injection of ketamine/xylazine prior to intranasal infection with influenza A/ $\mathrm{PR} / 8 / 34$ in $50 \mu 1$ serum-free Iscove's modified Dulbecco's medium (IMDM; Gibco). Unless otherwise specified, the standard dose used was $\mathrm{LD}_{100}$ for $\mathrm{MeCP}^{\mathrm{Tg} 3}$ mice, 3,500 egg-infectious doses $\left(\mathrm{EID}_{50}\right)$. Mice were euthanized based on a scoring system of 0 to 3 for three criteria: body weight changes $(0=$ normal up to $3=$ greater than $15 \%$ weight loss $)$, activity level changes $(0=$ normal up to $3=$ immobile $)$, and posture changes $(0=$ normal up to $3=$ lying prone). Euthanasia was performed when either a total score of 8 or a maximal score in 2 categories was reached.

Flow cytometry. After tissue preparation, cells were stained for 30 minutes at $4^{\circ} \mathrm{C}$ in flow cytometry buffer (1\% BSA, 2 mM EDTA, and $0.1 \%$ sodium azide in PBS). Flow cytometry antibodies against CD45 (clone 30-F11), CD11b (clone M1/70), CD11c (clone HL3), CD103 (clone M290), F4/80 (clone T452342), Ly6C (clone AL-21), Ly6G (clone 1A8), MHCII (clone M5/114.15.2), TCRb (clone H57-597), CD3 (clone 145-2C11), CD4 (clone RM4-5), CD8 (clone 53-6.7), B220 (clone RA3-6B2), NK1.1 (clone PK136), IgD (clone 11-26c.2a), CD19 (clone 1D3), Ter119 (clone TER-119), Siglec-F (clone E50-2440 or 1RNM44N), and IFN- $\gamma$ (clone XMG1.2) were purchased from BD Pharmingen or eBioscience. Flow cytometry antibodies against CD115 (clone AFS98) were purchased from Biolegend, and CCR2 (clone 
475301) from R\&D Systems. Tetramers were from MBL (OTI tetramer) or the Trudeau institute (NP and PA tetramers). For tetramer staining, samples were incubated for 30 minutes at room temperature. Samples were washed with $5 \mathrm{ml}$ flow cytometry buffer, centrifuged for 10 minutes at $300 \mathrm{~g}, 4^{\circ} \mathrm{C}$, and decanted. For intracellular staining, samples that had already been stained with extracellular antibodies were fixed and permeabilized using IC fixation buffer (eBioscience) and stained/washed using permeabilization buffer (eBioscience), according to the manufacturers' instructions. Samples were either fixed in 1\% paraformaldehyde (PFA) for later analysis or immediately run on a flow cytometer. Cytometers used were an LSR Fortessa (BD) in the University of Virginia Flow Cytometry Core, and a Gallios (Beckman Coulter) in the Center for Brain Immunology and Glia, University of Virginia.

Preparation of blood for flow cytometry. Blood samples for flow cytometry were collected after animal sacrifice via blood collection from the eye. Briefly, the eye was removed, and several drops of blood were collected into a heparinized tube to be used for whole blood cell count, and then the majority of blood was collected into flow cytometry buffer containing heparin (1\% BSA, 2 mM EDTA, 0.1\% sodium azide, $10 \mathrm{U} / \mathrm{ml}$ heparin in PBS), centrifuged at $300 \mathrm{~g}$ and $4^{\circ} \mathrm{C}$ for 10 minutes, supernatant was aspirated, and $5 \mathrm{ml}$ ACK lysis buffer was used to lyse RBCs by incubation for 5 minutes at room temperature. ACK buffer was washed by addition of $45 \mathrm{ml} 4^{\circ} \mathrm{C} \mathrm{PBS}$, and centrifugation at $300 \mathrm{~g}$ and $4^{\circ} \mathrm{C}$ for 10 minutes. Samples were then decanted and used for flow cytometry staining. Whole blood cell counts were obtained by 1:20 dilution of heparinized whole blood into acridine orange/propidium iodide staining solution in PBS and analysis on a Nexcelom Cellometer Auto 2000. Absolute blood cell counts were obtained by multiplication of the percentage of each population among total live cells measured via flow cytometry by the total live cell count.

Preparation of lung tissue for flow cytometry. After animals were euthanized, mice were transcardially perfused with $4^{\circ} \mathrm{C}$ PBS to remove blood, both systemically (via left ventricle) and within the pulmonary vasculature (right ventricle). Lungs were placed into $4^{\circ} \mathrm{C}$ IMDM (Gibco) until tissue collection was completed. Lungs were then minced and incubated at $37^{\circ} \mathrm{C}$ for 40 minutes, on a shaker, in petri dishes filled with 5 $\mathrm{ml}$ IMDM containing penicillin, streptomycin, and $183 \mathrm{U} / \mathrm{ml}$ collagenase type II (Worthington). Digested lungs were gently pressed and filtered through a 70- $\mu \mathrm{m}$ filter, washed in $50 \mathrm{ml}$ flow cytometry buffer, centrifuged at $300 \mathrm{~g}$ and $4^{\circ} \mathrm{C}$ for 10 minutes, decanted, RBC lysis was performed with ACK buffer (same method as described above in Preparation of blood for flow cytometry), and cells were used for flow cytometry staining. Lung cell counts were obtained by acridine orange/propidium iodide staining solution in PBS and analyzed on a Nexcelom Cellometer Auto 2000. Total lung cell counts were obtained by multiplication of the percentage of each population among total live cells measured via flow cytometry by the total live cell count.

Anti-PR8 antibody ELISA. Ninety-six-well ELISA plates were coated with influenza A/PR/8/34 virus stock diluted $1: 100$ in PBS $\left(7 \times 10^{7} \mathrm{EID}_{50}\right.$ per $\left.\mathrm{ml}\right)$ overnight at $4^{\circ} \mathrm{C}$. Plates were then washed 3 times with PBS containing $0.05 \%$ Tween-20 (PBST). Plates were then blocked with $2 \%$ BSA in PBST for 1 hour at room temperature, and washed 3 times with PBST. BAL fluid was then added to each well (50 $\mu 1$ volume) starting at 1:10 BAL diluted in PBS and then serially diluted 1:5. Samples were incubated at room temperature for 2 hours, and then wells were washed 3 times with PBST. Anti-mouse IgG or IgM conjugated to horseradish peroxidase (HRP) (SouthernBiotech) was diluted 1:10,000 in PBS and $50 \mu 1$ was added to each well for 1 hour at room temperature. Wells were again washed 3 times with PBST, and TMB substrate was added to each well $\mathrm{H}_{2} \mathrm{SO}_{4}$ stop solution $(100 \mu \mathrm{l}$ of $2 \mathrm{~N})$ was added to each well to stop the enzymatic reaction, and OD was measured at $450 \mathrm{~nm}$ on a 96 -well plate reader.

TCID ${ }_{50}$ assay. Madin-Darby canine kidney (MDCK) cells were grown in MEM supplemented with $10 \%$ FBS and $1 \%$ penicillin/streptomycin. Once cells reached $80 \%$ confluence, they were harvested by trypsinization $\left(5\right.$ minutes, $37^{\circ} \mathrm{C}$ ) and washed twice with media to quench trypsin. MDCK cells were then counted, split 1:4, and cultured overnight. The next day, cells were again harvested as described above, replated into 96-well plates, and allowed to adhere overnight at $37^{\circ} \mathrm{C}$. The following day, serum was washed off the cells using serum-free media, twice. Positive-control virus, negative control (PBS), or BAL fluid was prepared by mixing an initial $20 \mu \mathrm{l}$ of sample with $180 \mu \mathrm{l}$ of serum-free media containing trypsin, and serially diluting $1: 10$, seven times. Serial dilutions were added to MDCK cells in 96-well plates, in triplicate, and incubated for 3 days. The plates were spun down, and $50 \mu$ supernatant was pipetted into new 96-well round-bottom plates. Chicken RBCs (50 $\mu 1$ of $1 \%)$ in PBS were added and mixed. Plates were incubated at room temperature for 30 minutes and hemagglutination was assessed. The tissue culture infectious dose $\left(\mathrm{TCID}_{50}\right)$ is reported as the average number of wells with hemagglutination between technical replicates for each sample. 
Transfer of OTI T cells and assessment of proliferation during infection. $\mathrm{OTI}^{+/-} \mathrm{CD}^{+} \mathrm{T}$ cells were sorted by positive selection from either wild-type/ $\mathrm{OTI}^{+/-}$or $\mathrm{MeCP} 2^{\mathrm{Tg} 3} / \mathrm{OTI}^{+/-}$donors using $\mathrm{CD}^{+}$selection magnetic beads (Miltenyi Biotec) per the manufacturer's instructions. Sorted $\mathrm{OTI}^{+/-} \mathrm{CD}^{+} \mathrm{T}$ cells were CFSE labeled and 2 million cells were injected via tail vein into each host. One day later, mice were infected with OVA-expressing influenza $\mathrm{A} / \mathrm{PR} / 8$. On day 3.5, mice were sacrificed and mediastinal lymph nodes were collected to assess for $\mathrm{OTI}^{+/-} \mathrm{CD}^{+} \mathrm{T}$ cell proliferation by CFSE dilution.

Culture of BMDCs and restimulation of T cells with virus-loaded BMDCs. Bone marrow was collected from femurs and resuspended in DC media (RPMI without L-glutamine, 10\% FBS, penicillin/streptomycin, $0.05 \mathrm{mM} \beta$-mercaptoethanol, and $2 \mathrm{mM}$ L-glutamine) at a concentration of $10^{7}$ cells per ml. DC media (10 $\mathrm{ml}$ ) containing $20 \mathrm{ng} / \mathrm{ml} \mathrm{GM-CSF}$ (eBioscience) was placed in a non-TC-treated 100-mm petri dish, and $200 \mu \mathrm{l}$ of the concentrated bone marrow $\left(2 \times 10^{6}\right.$ bone marrow cells) were carefully pipetted as a colony in the middle of the petri dish. After resting for 10 minutes to allow cells to settle, petri dishes were moved to a tissue culture incubator at $37^{\circ} \mathrm{C}$, with care taken not to disperse the concentrated bone marrow cells in the center of the dish. On day 3 , an additional $10 \mathrm{ml}$ of DC media containing $20 \mathrm{ng} / \mathrm{ml} \mathrm{GM}$-CSF was slowly added to each petri dish so as not to disturb the cells. On days 6-9, BMDCs were harvested by collecting floating and semi-adherent cells in each petri dish. Cells were washed with serum-free RPMI twice. BMDC pellets were resuspended in $200 \mu 1$ serum-free RPMI, and mixed with $500 \mu 1$ stock influenza A/PR/8/34 virus for 5 minutes on ice, followed by incubation at $37^{\circ} \mathrm{C}$ for 30 minutes. Then, $20 \mathrm{ml}$ of prewarmed $37^{\circ} \mathrm{C}$ DC media containing $20 \mathrm{ng} / \mathrm{ml} \mathrm{GM}$-CSF was added, and cells were incubated at $37^{\circ} \mathrm{C}$ for 5 hours. BMDCs were then washed with DC media, counted, and mixed with effector cells (prepared via lung digestion, as described above) at a ratio of $1: 1$, in a 6-well non-TC-treated plate. Cells were incubated at $37^{\circ} \mathrm{C}$ for 1 hour, and then brefeldin A (eBioscience) was added to each well, followed by an additional 4-hour incubation at $37^{\circ} \mathrm{C}$. Cells were then collected and stained for cytokine production by flow cytometry.

$C B C$. For serial $C B C s$, lateral tail veins were lanced every other day and a minimal amount of blood was taken for analysis ( $\sim 50 \mu \mathrm{l})$. Samples were collected into EDTA tubes for anticoagulation and analyzed on a VetScan Abaxis HM5 CBC analyzer.

$B A L$. After mice were euthanized, skin and muscle over the trachea was removed, a small incision made in the trachea, a 25-G needle sheathed with soft plastic tubing was inserted into the trachea, secured with sutures, and used to administer $0.5 \mathrm{ml}$ PBS to lavage the lungs. Supernatants from the first lavage were used for cytokine, viral titer, and antibody titer analysis. For flow cytometric analysis, an additional $1 \mathrm{ml}$ of PBS was used to lavage the lungs a second time, and cells from both lavages were used for flow cytometry staining.

Luminex. BAL fluid samples were collected as described and stored at $-80^{\circ} \mathrm{C}$ until analysis. BAL fluid samples were submitted to and analyzed by the University of Virginia Flow Cytometry Core using Milliplex reagents per manufacturer's instructions (EMD Millipore).

Celecoxib and mifepristone treatment. Celecoxib (LKT Laboratories) and/or mifepristone (Sigma-Aldrich) was suspended in $0.4 \%$ carboxymethylcellulose, low-viscosity (Sigma-Aldrich) in PBS. Suspensions were prepared by vortexing followed by brief sonications in a water bath sonicator. Doses used were 25 or $100 \mathrm{mg} /$ $\mathrm{kg}$ for celecoxib, and $25 \mathrm{mg} / \mathrm{kg}$ mifepristone, given by daily i.p. injection starting 1 hour prior to infection.

Corticosterone measurement. Serum samples were collected after animal sacrifice via blood collection from the eye. Briefly, the eye was removed, and blood was collected in a $\mathrm{BD}$ microtainer serum gel tube. Blood was allowed to fully clot for 45 minutes at room temperature and serum was collected by centrifugation at $15,000 \mathrm{~g}$ for 90 seconds and collection of supernatant (serum). Serum samples were frozen at $-80^{\circ} \mathrm{C}$ until analysis by the University of Virginia Ligand Assay and Analysis Core using a mouse and rat corticosterone ELISA (IBL).

Bone marrow transplant. Four- to 10 -week-old mice were lethally irradiated with 1,000 rad, and injected with 5 million bone marrow cells via tail vein 5 hours after irradiation. Hosts were C57BL6 $\times$ FVB F1 hybrids (either $\mathrm{MeCP} 2^{\mathrm{Tg} 3}$ or wild type), and donor bone marrow was of the identical background strain. Donor mice were either $\mathrm{MeCP}^{\mathrm{Tg} 3}$ or wild type, and some donors were additionally $\mathrm{UBC}^{\mathrm{GFP} /+}$ in order to allow for assessment of engraftment efficiency prior to use of mice in downstream experiments. Mice were given water containing sulfamethoxazole and trimethoprim for 2 weeks after transplant. Infection experiments were performed 10 or more weeks after transplant.

Evans Blue assay for assessment of vascular permeability. Mice were injected i.p. with $400 \mu 1 \%$ Evans Blue solution in PBS 1 hour prior to collection. Mice were euthanized by Euthasol, and transcardially perfused with ice-cold PBS both systemically (left ventricle) and throughout the pulmonary vasculature 
(right ventricle) to remove vascular blood and Evans Blue dye. After weighing and photographing organs and BAL fluid, samples were mixed with 1 volume of $50 \%$ trichloroacetic acid and incubated overnight at $4^{\circ} \mathrm{C}$ to precipitate out proteins and other particulates. Samples were centrifuged at $15,000 \mathrm{~g}$ and $4^{\circ} \mathrm{C}$ for 30 minutes. Supernatants were analyzed by 96 -well plate reader at $620 \mathrm{~nm}$ (Multiskan FC, Fisher Scientific) and a standard curve was generated using known concentrations of Evans Blue dye in PBS mixed 1:1 with $50 \%$ trichloroacetic acid.

Pulmonary function measurement. Lung function was measured using a buffer-perfused mouse lung system (Hugo Sachs Elektronik). Briefly, mice were anesthetized with ketamine and xylazine and ventilated with room air at 100 strokes/min with a tidal volume of $7 \mu \mathrm{l} / \mathrm{g}$ body weight with a positive end expiratory pressure of $2 \mathrm{cmH}_{2} \mathrm{O}$ using the MINIVENT mouse ventilator (Hugo Sachs Elektronik). The animals were exsanguinated by transecting the inferior vena cava. The pulmonary artery was cannulated via the right ventricle, and the left ventricle was immediately tube-vented through a small incision at the apex of the heart. The lungs were then perfused at a constant flow of $60 \mu \mathrm{l} / \mathrm{g}$ body weight/min with Krebs-Henseleit buffer containing $2 \%$ albumin, $0.1 \%$ glucose, and $0.3 \%$ HEPES. The perfusate buffer and isolated lungs were maintained at $37^{\circ} \mathrm{C}$ throughout the experiment. Isolated lungs were allowed to equilibrate on the apparatus during a 5-minute stabilization period. After equilibration, data were recorded for an additional 10 minutes. Hemodynamic and pulmonary parameters were continuously recorded during this period by the PULMODYN data acquisition system (Hugo Sachs Elektronik).

Histology. Tissues were collected either with or without vascular perfusion and inflation of lungs with $4 \%$ PFA as indicated in each figure. Tissues were placed in 4\% PFA for 2 days, followed by transfer to $70 \%$ ethanol. Tissues were submitted to the University of Virginia Research Histology Core, where they were paraffin embedded, sectioned, mounted, and stained with H\&E.

Statistics. Flow cytometry data were analyzed using FlowJo (TreeStar). All statistical analyses were performed in Prism 6 (GraphPad) using the statistical tests described in each figure legend. $P$-value significance was set as follows: ${ }^{*} P<0.05,{ }^{* *} P<0.01$, and ${ }^{* * *} P<0.001$.

Study approval. All experiments and procedures complied with rules and regulations of the IACUC at the University of Virginia.

\section{Author contributions}

JCC, TJB, and JK designed the research. JCC, JH, TSK, AL, EKM, AKS, and IS performed the research. KST and TJB analyzed the histology. JCC, TJB, and JK wrote the paper.

\section{Acknowledgments}

We thank the members of the Kipnis and Braciale labs, as well as the members of the Center for Brain Immunology and Glia (BIG) and the Carter Immunology Center (CIC) at the University of Virginia for their valuable comments during multiple discussions of this work. We thank Sanford Feldman for his assistance in CBC data collection and discussion regarding data. We thank Tajie Harris for the use of her bright-field microscope and for providing OTI tetramer. We thank J. David Peske and the lab of Victor H. Engelhard for providing the $\operatorname{Tg}($ TcraTcrb) $1100 \mathrm{Mjb}$ mouse strain. This work was primarily supported by the NIH/NIAID NRSA 5F30AI109984 (to J.C.C.), a grant from the International Rett Syndrome Foundation (IRSF; to J.K.), Rett Syndrome Research Trust (RSRT; to J.K.), NIH/NINDS 5R01NS081026 (to J.K.), USPHS R01 AI-15608 (to T.J.B), and R01 HL-33391 (to T.J.B.).

Address correspondence to: Thomas J. Braciale, P.O. Box 801386, Carter Immunology Center, University of Virginia, Charlottesville, Virginia 22908, USA. Phone: 434.982.3858; E-mail: tjb2r@virginia.edu. Or to: Jonathan Kipnis, P.O. Box 801392, Department of Neuroscience, University of Virginia, Charlottesville, Virginia 22908, USA. Phone: 434.982.3858; E-mail: kipnis@virginia.edu.

1. Ben-Shachar S, Chahrour M, Thaller C, Shaw CA, Zoghbi HY. Mouse models of MeCP2 disorders share gene expression changes in the cerebellum and hypothalamus. Hum Mol Genet. 2009;18(13):2431-2442.

2. Chahrour M, et al. MeCP2, a key contributor to neurological disease, activates and represses transcription. Science. 2008;320(5880):1224-1229.

3. Amir RE, Van den Veyver IB, Wan M, Tran CQ, Francke U, Zoghbi HY. Rett syndrome is caused by mutations in X-linked MECP2, encoding methyl-CpG-binding protein 2. Nat Genet. 1999;23(2):185-188. 
4. Van Esch H, et al. Duplication of the MECP2 region is a frequent cause of severe mental retardation and progressive neurological symptoms in males. Am J Hum Genet. 2005;77(3):442-453.

5. Ramocki MB, Tavyev YJ, Peters SU. The MECP2 duplication syndrome. Am J Med Genet A. 2010;152A(5):1079-1088

6. Friez MJ, et al. Recurrent infections, hypotonia, and mental retardation caused by duplication of MECP2 and adjacent region in Xq28. Pediatrics. 2006;118(6):e1687-e1695.

7. Yang T, et al. Overexpression of methyl-CpG binding protein 2 impairs T(H)1 responses. Sci Transl Med. 2012;4(163):163ra158.

8. Balmer D, Arredondo J, Samaco RC, LaSalle JM. MECP2 mutations in Rett syndrome adversely affect lymphocyte growth, but do not affect imprinted gene expression in blood or brain. Hum Genet. 2002;110(6):545-552.

9. Jiang S, et al. MeCP2 reinforces STAT3 signaling and the generation of effector $\mathrm{CD}^{+} \mathrm{T}$ cells by promoting miR-124-mediated suppression of SOCS5. Sci Signal. 2014;7(316):ra25.

10. Li C, et al. MeCP2 enforces Foxp3 expression to promote regulatory T cells' resilience to inflammation. Proc Natl Acad Sci USA. 2014;111(27):E2807-E2816.

11. O'Driscoll CM, Kaufmann WE, Bressler JP. MeCP2 deficiency enhances glutamate release through NF-kB signaling in myeloid derived cells. J Neuroimmunol. 2013;265(1-2):61-67.

12. O'Driscoll CM, Lima MP, Kaufmann WE, Bressler JP. Methyl CpG binding protein 2 deficiency enhances expression of inflammatory cytokines by sustaining NF- $\mathrm{kB}$ signaling in myeloid derived cells. J Neuroimmunol. 2015;283:23-29.

13. Cronk JC, et al. Methyl-CpG binding protein 2 regulates microglia and macrophage gene expression in response to inflammatory stimuli. Immunity. 2015;42(4):679-691.

14. Derecki NC, et al. Wild-type microglia arrest pathology in a mouse model of Rett syndrome. Nature. 2012;484(7392):105-109.

15. Jin LW, et al. Dysregulation of glutamine transporter SNAT1 in Rett syndrome microglia: a mechanism for mitochondrial dysfunction and neurotoxicity. J Neurosci. 2015;35(6):2516-2529.

16. Maezawa I, Jin LW. Rett syndrome microglia damage dendrites and synapses by the elevated release of glutamate. $J$ Neurosci. 2010;30(15):5346-5356.

17. Collins AL, et al. Mild overexpression of MeCP2 causes a progressive neurological disorder in mice. Hum Mol Genet. 2004;13(21):2679-2689.

18. Koelsch KA, et al. Functional characterization of the MECP2/IRAK1 lupus risk haplotype in human T cells and a human MECP2 transgenic mouse. J Autoimmun. 2013;41:168-174.

19. Bauer M, et al. Infectious and immunologic phenotype of MECP2 duplication syndrome. J Clin Immunol. 2015;35(2):168-181.

20. Graham MB, Dalton DK, Giltinan D, Braciale VL, Stewart TA, Braciale TJ. Response to influenza infection in mice with a targeted disruption in the interferon gamma gene. J Exp Med. 1993;178(5):1725-1732.

21. Hogquist KA, Jameson SC, Heath WR, Howard JL, Bevan MJ, Carbone FR. Pillars article: T cell receptor antagonist peptides induce positive selection. Cell. 1994. 76: 17-27. J Immunol. 2012;188(5):2046-2056.

22. Tisoncik JR, Korth MJ, Simmons CP, Farrar J, Martin TR, Katze MG. Into the eye of the cytokine storm. Microbiol Mol Biol Rev. 2012;76(1):16-32.

23. Braun S, Kottwitz D, Nuber UA. Pharmacological interference with the glucocorticoid system influences symptoms and lifespan in a mouse model of Rett syndrome. Hum Mol Genet. 2012;21(8):1673-1680.

24. Nuber UA, et al. Up-regulation of glucocorticoid-regulated genes in a mouse model of Rett syndrome. Hum Mol Genet. 2005;14(15):2247-2256.

25. Samaco RC, Mandel-Brehm C, McGraw CM, Shaw CA, McGill BE, Zoghbi HY. Crh and Oprm1 mediate anxiety-related behavior and social approach in a mouse model of MECP2 duplication syndrome. Nat Genet. 2012;44(2):206-211.

26. Coutinho AE, Chapman KE. The anti-inflammatory and immunosuppressive effects of glucocorticoids, recent developments and mechanistic insights. Mol Cell Endocrinol. 2011;335(1):2-13.

27. Matute-Bello G, et al. Optimal timing to repopulation of resident alveolar macrophages with donor cells following total body irradiation and bone marrow transplantation in mice. J Immunol Methods. 2004;292(1-2):25-34

28. Ghoneim HE, Thomas PG, McCullers JA. Depletion of alveolar macrophages during influenza infection facilitates bacterial superinfections. J Immunol. 2013;191(3):1250-1259.

29. Tumpey TM, et al. Pathogenicity of influenza viruses with genes from the 1918 pandemic virus: functional roles of alveolar macrophages and neutrophils in limiting virus replication and mortality in mice. $J$ Virol. 2005;79(23):14933-14944.

30. Tate MD, Pickett DL, van Rooijen N, Brooks AG, Reading PC. Critical role of airway macrophages in modulating disease severity during influenza virus infection of mice. J Virol. 2010;84(15):7569-7580.

31. Leoncini S, et al. Cytokine dysregulation in MECP2- and CDKL5-related Rett syndrome: relationships with aberrant redox homeostasis, inflammation, and $\omega-3$ PUFAs. Oxid Med Cell Longev. 2015;2015:421624.

32. De Felice C, et al. Inflammatory lung disease in Rett syndrome. Mediators Inflamm. 2014;2014:560120.

33. Nouailles G, et al. CXCL5-secreting pulmonary epithelial cells drive destructive neutrophilic inflammation in tuberculosis J Clin Invest. 2014;124(3):1268-1282.

34. Koltsova EK, Ley K. The mysterious ways of the chemokine CXCL5. Immunity. 2010;33(1):7-9.

35. Mei J, et al. CXCL5 regulates chemokine scavenging and pulmonary host defense to bacterial infection. Immunity. 2010;33(1):106-117.

36. Jeyaseelan S, et al. Induction of CXCL5 during inflammation in the rodent lung involves activation of alveolar epithelium. Am $J$ Respir Cell Mol Biol. 2005;32(6):531-539.

37. McNab F, Mayer-Barber K, Sher A, Wack A, O'Garra A. Type I interferons in infectious disease. Nat Rev Immunol. 2015;15(2):87-103.

38. Sztainberg Y, et al. Reversal of phenotypes in MECP2 duplication mice using genetic rescue or antisense oligonucleotides. Nature. 2015;528(7580):123-126. 